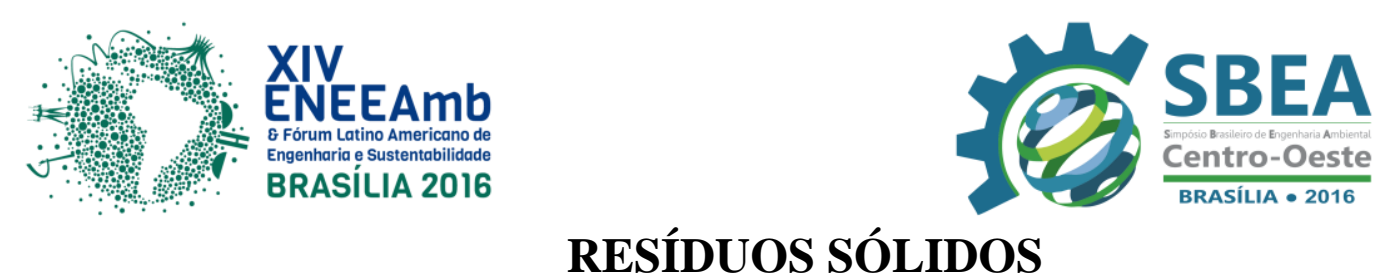

\title{
PROJETO PILOTO DE COMPOSTAGEM NOS CAMPI I E II DO CEFET-MG
}

\author{
Ítalo Cordeiro e Lellis - italocordlellis@ gmail.com \\ Centro Federal de Educação Tecnológica de Minas Gerais (CEFET-MG) \\ Franciele Aparecida Plotásio Duarte - francieleplotasio@ gmail.com \\ Centro Federal de Educação Tecnológica de Minas Gerais (CEFET-MG) \\ Jéssica Elorde Freitas - jehelorde@gmail.com \\ Centro Federal de Educação Tecnológica de Minas Gerais (CEFET-MG) \\ Jéssica Thebaldi Victoriano - jethebaldi@ gmail.com \\ Centro Federal de Educação Tecnológica de Minas Gerais (CEFET-MG) \\ Valéria Cristina Palmeira Zago - valzagomg@ gmail.com \\ Professora Associada - Departamento de Ciência e Tecnologia Ambiental \\ Centro Federal de Educação Tecnológica de Minas Gerais (CEFET-MG)
}

\begin{abstract}
Resumo: Atualmente um dos maiores desafios para a sociedade é saber equilibrar a geração de resíduos sólidos que vem ocorrendo de forma excessiva e sua disposição final ambientalmente adequada. A compostagem surge, dentro deste contexto, como uma técnica simples e de fácil implantação para reduzir a geração dos materiais orgânicos, aumentar a vida útil dos aterros sanitários, produzindo um composto rico em húmus e nutriente minerais. Dessa forma, este trabalho teve como objetivo avaliar a viabilidade de compostagem dos resíduos orgânicos gerados nos restaurantes universitários dos Campi I e II do Centro Federal de Educação Tecnológica de Minas Gerais (CEFET-MG), localizado em Belo Horizonte, através do monitoramento dos parâmetros $\mathrm{pH}$, temperatura e umidade durante o processo. A compostagem foi realizada na estação chuvosa, com ocorrência de precipitações constantes, o que se refletiu nos teores de umidade acima do ideal no início da compostagem e em temperaturas máximas abaixo de $60^{\circ} \mathrm{C}$, na fase termófila. No entanto, não foi observada indícios de anaerobiose, como odores desagradáveis ou lixiviação de chorume. $\mathrm{O}$ pH manteve o comportamento correspondente às diferentes fases de decomposição dos materiais orgânicos. A maturação do composto ocorreu aproximadamente aos 120 dias. Após o peneiramento, obteve-se um aproveitamento de 73,55\% do composto. Concluiu-se que mesmo com os teores de umidade elevados, foi possível a produção de composto orgânico, evitando-se significativamente a destinação de resíduos ao aterro sanitário e redução de custos para a instituição. Fica clara a importância da continuidade do estudo, a fim de determinar a qualidade nutricional do composto.
\end{abstract}

Palavras-chave: Compostagem, Resíduos orgânicos, Restaurante universitário. 


\section{INTRODUÇÃO}

Um dos maiores desafios para a sociedade moderna é o equacionamento da geração excessiva e da disposição final ambientalmente segura dos resíduos sólidos. Esta produção de imensas quantidades de resíduos deve-se ao crescimento e a longevidade da população aliados à intensa urbanização e à expansão do consumo de novas tecnologias (JACOBI \& BESEN, 2011). Para Siqueira e Moraes (2009) os resíduos sólidos urbanos gerados resultam em risco à saúde pública, provocam degradação ambiental, além dos aspectos sociais, econômicos e administrativos envolvidos na questão.

Segundo Santos (2007) para solucionar a problemática que envolve os resíduos sólidos, como o uso inadequado dos recursos naturais, consumismo exagerado com geração de resíduos e saturação de aterros sanitários, disposição final inadequada acarretando poluição, é necessário que os municípios adotem o gerenciamento integrado de resíduos sólidos que compreendem a redução da geração destes, a reutilização, a reciclagem de materiais e a compostagem que trata resíduos orgânicos, dando a este uma nova utilidade.

Uma das maneiras de desviar os resíduos do lixão a céu aberto, do aterro sanitário ou controlado, é o modelo gerencial de compostagem, que além desta vantagem promove uma nova utilização para a matéria orgânica (SANTOS, 2007). Outra vantagem, segundo Mello-Peixoto et al. (2014) é a simplicidade de implantação da composteira, podendo ser instalada até dentro das casas, de preferência em quintais.

A prática de compostagem é bastante antiga; por toda a história das civilizações há relatos de que, desde muito tempo é utilizado pelo homem do campo, onde utilizava restos de produtos orgânicos, tanto de origem animal como vegetal, para incorporação ao solo, objetivando promover melhorias em suas propriedades físicas, biológicas e químicas em busca de melhores produções (VITAL et al., 2012).

A compostagem é o conjunto de técnicas aplicadas para controlar a decomposição de materiais orgânicos, com a finalidade de obter no menor tempo possível, um material orgânico mais estável, rico em húmus e nutriente minerais, resistente à ação de espécies consumidoras, com atributos físicos, químicos e biológicos, superiores àqueles encontrados nas matérias primas. Produzindo assim uma cadeia de produção com características sustentáveis, que utiliza restos e sobras que antes teriam um destino qualquer para otimizar a produção com adubo de alto valor biológico. Dessa forma, a compostagem representa importante opção para dar destino aos resíduos rurais e urbanos como: resíduos de restaurantes, hotéis, indústrias, supermercados, entre outros (MELLO-PEIXOTO et al., 2014; VITAL et al., 2012).

Conforme Inácio \& Miller (2009) por envolver grupos variados de microrganismos em sucessão que transformam o substrato em decomposição, a compostagem é considerada um processo biológico e ecológico complexo. Um determinante da atividade microbiana é a temperatura, pois é um forte fator seletivo sobre os organismos e influi no fluxo de ar e na perda de umidade. A temperatura e a sucessão de grupos de microrganismos se influenciam mutuamente no processo de compostagem, a observação da temperatura resultante da concentração de calor, indica o bom andamento do processo em fases.

Vital et al. (2012) acrescenta que no processo de decomposição da matéria orgânica na compostagem, as quantidades de nutrientes disponíveis nos restos orgânicos podem ser revertidas para auxiliar na nutrição das plantas dos jardins, além de manter a fauna edáfica benéfica do solo. 
Porém para que se obtenha um composto aplicável agronomicamente é necessária à separação prévia do material não orgânico para que sejam reduzidas as chances de contaminação e, assim, o composto possa ser de melhor qualidade (SANTOS et al., 2014).

Dentro desta perspectiva, o presente trabalho teve como objetivo realizar um compostagem em escala piloto utilizando-se os resíduos orgânicos de preparo gerados nos Restaurantes Universitários (RU's) e os resíduos de poda das árvores e gramados dos jardins dos Campi I e II (Belo Horizonte), do Centro Federal de Educação Tecnológica de Minas Gerais (CEFET-MG).

\section{METODOLOGIA}

Neste estudo, utilizaram-se os resíduos de preparos e cortes de frutas e hortaliças, como: cascas, folhas externas e talos além de folhas e ramos de podas de árvores e gramados dos jardins do campus II. Os resíduos orgânicos dos refeitórios (Campi I e II) foram acondicionamos durante cinco dias consecutivos (16 a 20/11 de 2015) em uma sala refrigerada no Campus I, até o momento da montagem da leira de compostagem.

A composteira foi montada no dia 20 de novembro de 2015 em um espaço localizado no Campus II, em leira modelo "Windrow", formato trapezoidal, diretamente sobre o solo. Os resíduos de poda foram picados de modo a reduzir as partículas a um tamanho de aproximadamente $1 \mathrm{~cm}$. Para a montagem da leira foram utilizados um total de $215 \mathrm{~kg}$ de resíduos do preparo dos cardápios e $176 \mathrm{~kg}$ de resíduos de poda. Os resíduos da cozinha foram armazenados durantes o período de 16 a 20/11 de 2015, em uma sala refrigerada no Campus I, até o momento da montagem da leira.

A leira foi construída intercalando-se camadas de resíduos de alimentos $(05 \mathrm{~cm})$ e resíduos de podas $(15 \mathrm{~cm})$. No término de cada camada, os resíduos foram irrigados. Este procedimento foi realizado continuamente até que a leira atingisse aproximadamente $1,2 \mathrm{~m}$ de altura, com volume inicial de $1,17 \mathrm{~m}^{3}$.

Adotou-se para o manuseio da leira, equipamentos de Proteção Individual - EPIs (luvas, botas e máscaras) para garantir a segurança da equipe e outros instrumentos como enxada, pá e fita métrica.

Para análise dos parâmetros $\mathrm{pH}$ e umidade foi utilizado o equipamento Instrutherm $\mathrm{pH} 2500$, estabelecendo-se para o monitoramento, o ponto central da leira (altura $\mathrm{x}$ largura). Já para o monitoramento da temperatura foram utilizadas três alturas diferentes da leira: inferior (10 $\mathrm{cm}$ da base), média (meio da leira) e superior (10 $\mathrm{cm}$ do topo), utilizando-se o Termômetro digital, modelo ITTH 1400, com haste de $90 \mathrm{~cm}$ de comprimento. As leiras foram revolvidas com 15 e 60 dias após a sua montagem, irrigando-a novamente.

A compostagem foi conduzida durante o período de 20/11/2015 a 10/03/2016. O processo foi interrompido quando a temperatura da leira se igualou à temperatura ambiente.

O composto foi peneirado, utilizando-se uma peneira com malha de $5 \mathrm{~mm}$, retendo o material orgânico que não foi totalmente decomposto. A partir dos valores de massas foi possível estabelecer uma proporção de aproveitamento.

\section{RESULTADOS E DISCUSSÕES}

Segundo Kiehl (1998), as temperaturas ótimas para a compostagem são, em sua fase mesófila $\left(25\right.$ a $\left.40^{\circ} \mathrm{C}\right)$ e termófila $\left(50\right.$ a $\left.55^{\circ} \mathrm{C}\right)$. Em relação ao monitoramento da temperatura, pôde-se observar que a fase mesófila se desenvolveu rapidamente, pois a partir do quinto dia, os valores alcançaram 58 e $59^{\circ} \mathrm{C}$, nas alturas superior e média da leira, 
respectivamente. No entanto, a parte inferior da leira só atingiu essa fase no $10^{\circ}$ dia. A fase termófila ocorreu até o $25^{\circ}$ dia (Gráfico 1 ).

Depois de iniciada a fase termófila, o ideal é controlar a temperatura entre $55 \mathrm{e}$ $65^{\circ} \mathrm{C}$. Esta é a faixa que permite a máxima intensidade de atividade microbiológica. Acima de $65^{\circ} \mathrm{C}$ a atividade microbiológica cai e o ciclo de compostagem fica mais longo (FERNANDES \& SILVA, 1996). Após os revolvimentos, que ocorreram nos $15^{\circ}$ e $60^{\circ}$ dias, observaram-se reduções nas temperaturas. Após o $60^{\circ}$ dia, as temperaturas mantiveram-se abaixo dos $35^{\circ} \mathrm{C}$, equiparando-se à temperatura ambiente desde então, até o final da compostagem.

Gráfico 1: Temperatura $\left({ }^{\circ} \mathrm{C}\right)$ em três diferentes alturas da leira - piloto durante o desenvolvimento do experimento (120 dias).

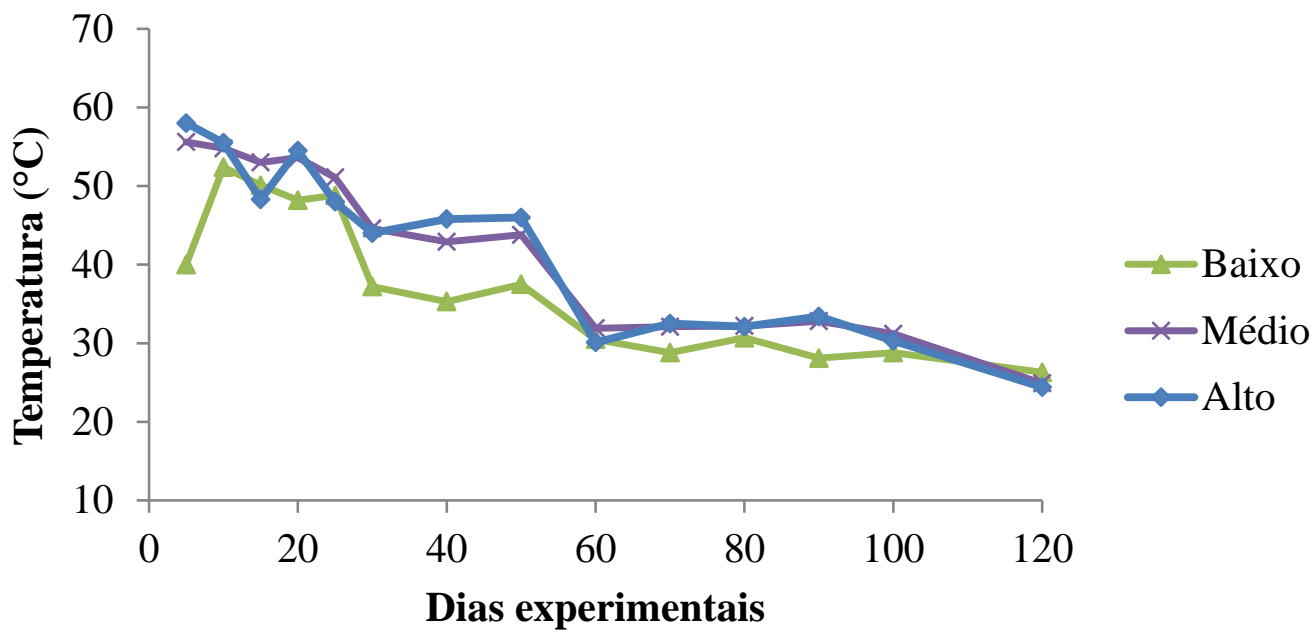

Outro aspecto importante a ser considerado refere-se à umidade, que apresentou valores entre 50 e $90 \%$ durante a condução da compostagem (Gráfico 2). No entanto, na etapa final do processo, a umidade alcançou os teores de $40 \%$, adequados segundo Pereiro Neto e Lelis (1999). 
Gráfico 2: Valores de umidade (\%) da composteira piloto durante o desenvolvimento do experimento (120 dias).

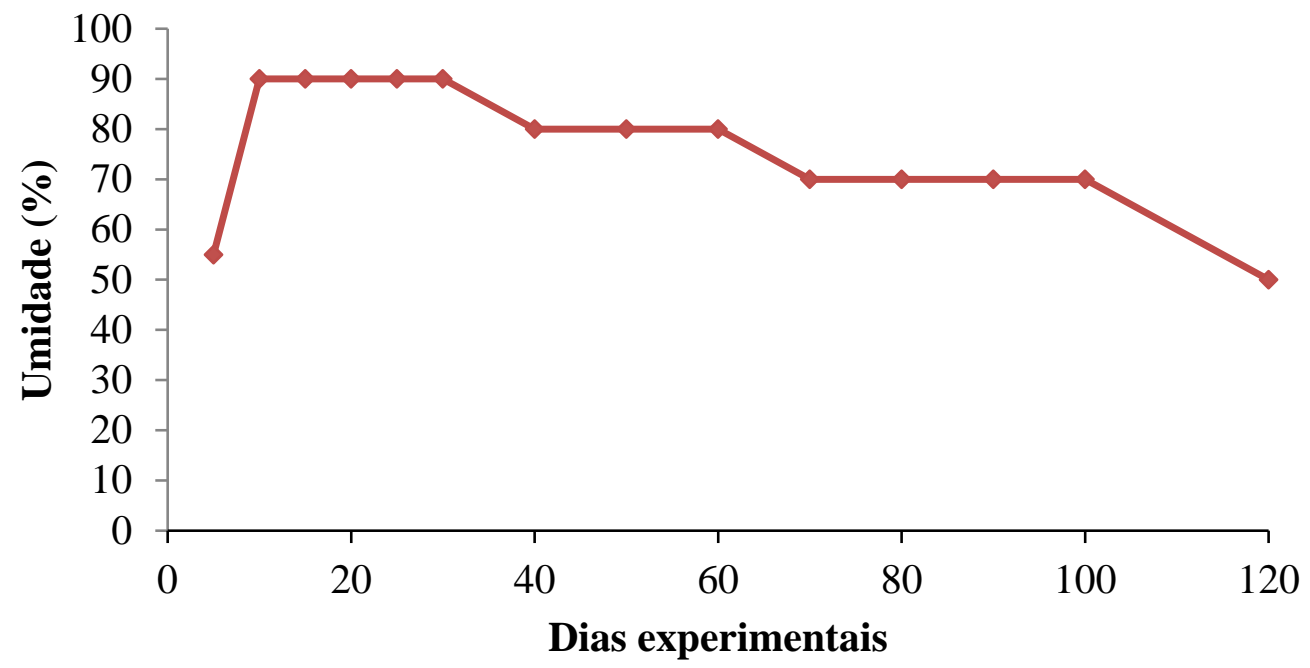

Baseando-se em Lima (2015), os valores de umidade maiores do que $65 \%$ podem afetar a aeração, favorecendo o processo de anaerobiose. A alta taxa de umidade verificada pode ser explicada pelos elevados índices de precipitação nos meses de dezembro/2015 e janeiro/2016. No entanto, não se observaram indicadores de anaerobiose, como odores, atração de insetos ou lixiviação de chorume, durante o processo de compostagem.

Em relação às análises de $\mathrm{pH}$, observou-se na fase inicial da compostagem (mesófila) a queda do pH devido à formação de ácidos orgânicos, variando aproximadamente de 6,6 a 5,4 (Gráfico 3). Porém, na fase termófila foi identificada uma rápida elevação do $\mathrm{pH}$, que segundo Fernandes e Silva (1996) é explicada pela hidrólise das proteínas e liberação de amônia, mantendo-se até a fase final em uma faixa entre 6,5 e 7,5, valores considerados plenamente satisfatório à atividade microbiana (INÁCIO \& MILLER, 2009).

Gráfico 3: Valores de $\mathrm{pH}$ da composteira piloto durante o desenvolvimento do experimento (120 dias).

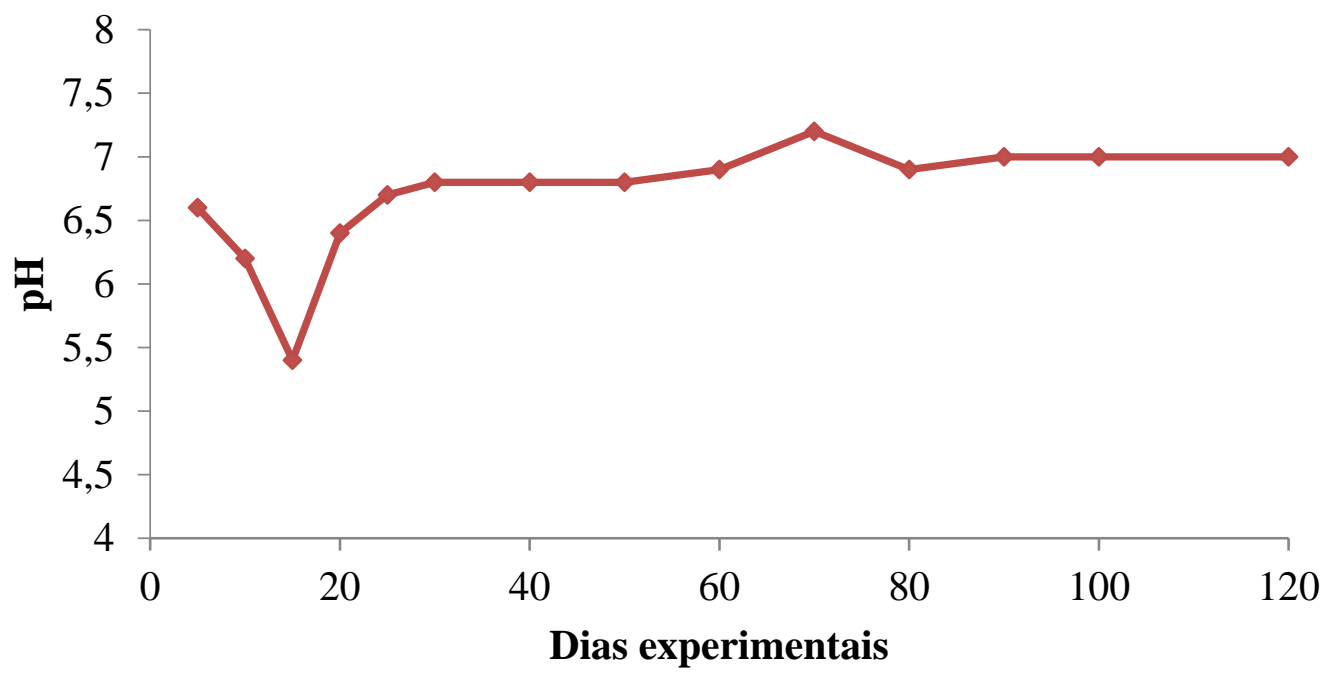



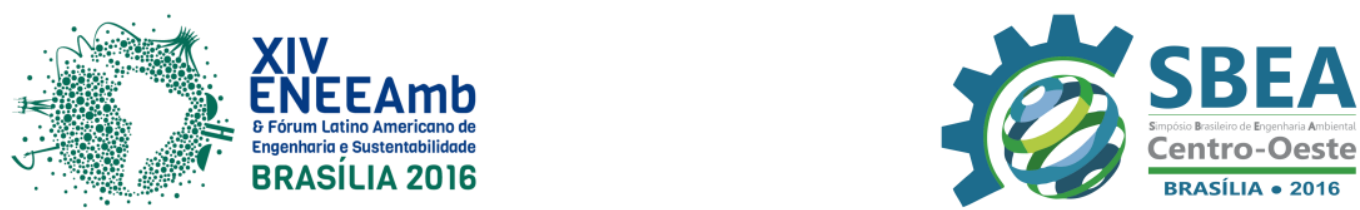

Outro aspecto importante a ser considerado refere-se a média de aproveitamento do composto final. A unidade - piloto de compostagem obteve um aproveitamento de $73,55 \%$ do composto final, após o peneiramento.

Segundo Massukado (2008), caso o material compostável fosse separado na fonte e destinado para tratamento específico, evitar-se-ia o acúmulo de matéria orgânica nos aterros sanitários, sendo possível aumentar a vida útil do mesmo, ou então para o mesmo período a construção de aterros menores. Há ainda ganhos econômicos com a redução de custos com transporte (caso a compostagem acontecer mais próxima dos geradores), disposição final e tratamento do chorume.

\section{CONSIDERAÇÕES FINAIS}

Em face do exposto, pode-se concluir que a compostagem apresentou-se como uma prática simples e de fácil implantação na instituição, reutilizando de forma eficiente os resíduos do preparo de alimentos produzidos nos refeitórios e de jardinagem, contribuindo para o aumento da vida útil dos aterros sanitários. Outro fator positivo, é a redução dos gastos da instituição com caçambas para recolhimento dos resíduos da jardinagem, por isso sugere-se a continuidade do estudo, a fim de determinar a qualidade do composto com análises de micro e macronutrientes e estabelecer o seu uso como adubo das áreas verdes da instituição.

Quando a composteira é montada da forma correta, os resultados são positivos como foi o caso desta pesquisa. Foi perceptível que durante todo o processo não houve atração de insetos ou animais, nem mesmo odor na região onde a composteira foi implantada. Apesar do elevado índice de precipitação durante o período em que o processo estava em andamento, com o correto e frequente monitoramento dos parâmetros de temperatura, umidade e $\mathrm{pH}$, este fato não afetou no composto final.

Outro problema enfrentado durante o processo foi ausência ou incompleta segregação dos resíduos por parte dos funcionários do refeitório, dificultando a montagem da pilha e tornando o processo de decomposição mais lento.

Portanto, conclui-se que, apesar da composteira ter mostrado viável para a instituição, faz-se necessário um trabalho contínuo de educação ambiental para sensibilização dos servidores dos refeitórios na segregação dos resíduos orgânicos direto na fonte geradora, evitando a contaminação dos resíduos e até mesmo a inviabilização do processo de compostagem.

\section{REFERÊNCIAS BIBLIOGRÁFICAS}

FERNANDES, F.; SILVA, S. M. C. P. da Manual Prático para a compostagem de Biossólidos. Londrina: Instituto de Pesquisas Agronômicas do Parána, 1996.

INÁCIO, C. de T.; MILLER, P. R. M. Compostagem: Ciência e prática para a gestão de resíduos orgânicos. Rio de Janeiro: Embrapa Solos, 2009.

JACOBI, P. R.; BESEN, G. R. Gestão de resíduos sólidos em São Paulo: desafios da sustentabilidade. Estudos Avançados, São Paulo, v. 25, n. 71, p.135-158, Jan/Abr. 2011. 

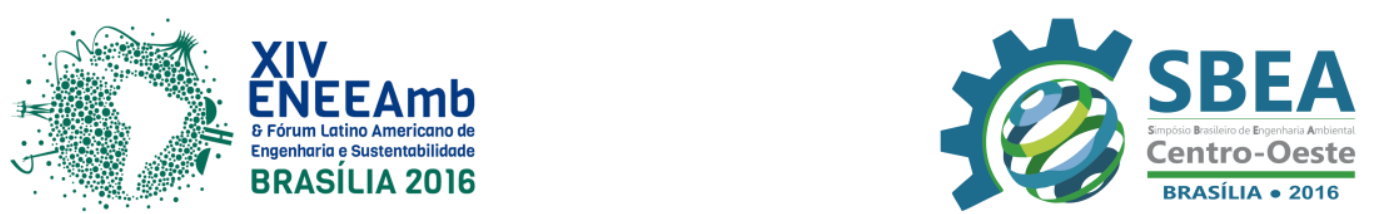

KIEHL, E. J. Manual de compostagem: maturação e qualidade do composto. Ed. Agronômica Ceres, 1998.

LIMA, L. C. Avaliação de Diferentes Fontes de Carbono e Nitrogênio para Compostagem dos Resíduos Orgânicos do Restaurante Universitário da UFLA. 2015. 94 f. Dissertação (Mestrado) - Curso de Recursos Hídricos em Sistemas Agrícolas, Universidade Federal de Lavras, Lavras, 2015.

MASSUKADO, L. M. Desenvolvimento do processo de compostagem em unidade descentralizada e proposta de software livre para o gerenciamento municipal dos resíduos sólidos domiciliares. 2008. 204 p. Tese (Doutorado em Ciências da engenharia ambiental) - Escola de Engenharia de São Carlos, Universidade de São Paulo, São Carlos.

MELlO-PEIXOTO, E. C. T. et al. Compostagem: construções e benefícios. In: Congresso Paranaense de Agroecologia, 1., 2014, Pinhais. Pinhais: Cadernos de Agroecologia, 2014. p. $1-5$.

SANTOS, A. T. L. et al. Aproveitamento da fração orgânica dos resíduos sólidos para produção composto orgânico. Revista Brasileira de Ciências da Amazônia, Rondônia, v. 3, n. 1, p.15-28, 2014.

SANTOS, H. M. N. dos. Educação ambiental por meio da compostagem dos resíduos sólidos orgânicos em escolas públicas de Araguari-MG. 2007. 160 f. Dissertação (Mestrado) - Curso de Engenharia Civil, Universidade Federal de Uberlândia, Uberlândia, 2007.

SIQUEIRA, M. M.; MORAES, M. S. de. Saúde Coletiva, resíduos sólidos urbanos e os catadores de lixo. Ciência \& Saúde Coletiva, Rio de Janeiro, v. 14, n. 6, p.1-9, dez. 2009.

VITAL, A. de F. M. et al. Implementação de uma composteira e de um minhocário como prática de educação ambiental visando a gestão de resíduos sólidos do cdsa. Revista Didática Sistêmica, Rio Grande, v. 14, n. 2, p.78-94, 2012. 